\title{
Interpreting Umbilical Cord Blood Gases Cord Occlusion with Terminal Fetal Bradycardia: Part V
}

Jeffrey Pomerance, MD, MPH

\section{"The umbilical cord blood gas results obviously do not reflect the severe respiratory and metabolic acidosis present in a clinically dead infant. The blood sample drawn through the UVC during resuscitation reflects this very clearly."}

\section{Case 15: Cord Prolapse}

The mother was a 20 -year-old, gravida 3 , para 1 , aborta 1 , with an intrauterine pregnancy at 38 0/7 weeks gestation.(1) She presented at the hospital in active labor. The cervix was completely dilated and effaced, and the breech was at plus three station with a non-pulsatile cord protruding from the vagina. The mother was taken emergently for a vaginal delivery with the assistance of Piper forceps. A male infant was delivered with Apgar scores of 0, 0, and 0 at one, five, and 10 minutes, respectively. On further questioning, the mother stated she felt a gush of water and something "funny" near her leg while in transit to the hospital. The exact time from the cord prolapse to arrival at the hospital was unknown but probably exceeded 20 minutes.

Cord blood gas results were as follows:

\begin{tabular}{|c|c|c|}
\hline & Umbilical Vein & Umbilical Artery \\
\hline pH & 7.24 & 7.10 \\
\hline $\mathrm{PcO}_{2} \underset{(\mathrm{kPa})}{(\mathrm{mmHg})}$ & $\begin{array}{l}55 \\
7.33\end{array}$ & $\begin{array}{l}71 \\
9.47\end{array}$ \\
\hline $\mathrm{Po}_{2} \underset{(\mathrm{kPa})}{(\mathrm{mmHg})}$ & $\begin{array}{l}20 \\
2.67\end{array}$ & $\begin{array}{l}8 \\
1.07\end{array}$ \\
\hline $\mathrm{BD}(\mathrm{mmol} / \mathrm{L})$ & 4 & 8 \\
\hline
\end{tabular}

Attempts to resuscitate the infant were not successful. During resuscitation, an umbilical venous catheter was placed, and blood was drawn.

Results of the umbilical venous catheter blood gas were:

\begin{tabular}{|lc|l|}
\hline & & UVC \\
\hline $\mathbf{p H}$ & & 6.68 \\
\hline $\mathrm{PcO}_{2}$ & $\begin{array}{c}(\mathbf{m m H g}) \\
(\mathbf{P P a})\end{array}$ & $\begin{array}{l}120 \\
16.00\end{array}$ \\
\hline $\mathrm{Po}_{2}$ & $\begin{array}{c}(\mathbf{m m H g}) \\
(\mathbf{k P a})\end{array}$ & 6 \\
& 0.80 \\
\hline $\mathrm{BD}(\mathbf{m m o l} / \mathbf{L})$ & 22 \\
\hline
\end{tabular}

\section{Interpretation}

The umbilical venous blood gas sample has a borderline low $\mathrm{pH}$, a mild elevation of the $\mathrm{PCO}_{2}$ and a normal $\mathrm{PO}_{2}$ and base deficit. The umbilical arterial blood gas sample has a modestly low $\mathrm{pH}$, a mildly elevated $\mathrm{PCO}_{2}$ and a mildly elevated base deficit. The difference between the umbilical venous and arterial $\mathrm{pH}$ is widened $(>0.10)$, as is the difference between base deficits $(\geq 4)$. This suggests that following cord prolapse, the umbilical cord was occluded; however, umbilical arterial blood flow was briefly restored while the umbilical vein remained occluded.

Cord prolapse has been reported to occur in $0.24 \%$ of vertex presentations, $3.5 \%$ of breech presentations (frank breech $0.5 \%$, complete breech $5 \%$, footling breech $15 \%(2)$ ), and $9.6 \%$ of transverse presentations. $(3,4)$ Other factors besides abnormal fetal presentation $(51 \%)$ associated with cord prolapse include prematurity $(38 \%)$, obstetric manipulation $(19 \%)$, multiparity $(13 \%)$, multiple gestations (10\%), and placental problems (8\%).(3) Umbilical cord accidents are most frequent in the presence of a long cord. (5)

The umbilical cord blood gas results obviously do not reflect the severe respiratory and metabolic acidosis present in a clinically dead infant. The blood sample drawn through the UVC during resuscitation reflects this very clearly. Total cord occlusion from cord prolapse has completely interrupted the flow of blood to and from the placenta. The umbilical cord blood gas values do not reflect the infant's current status, only the status just before the occlusion. There is insufficient metabolically active tissue in the umbilical cord (largely water) to either utilize sufficient oxygen or produce sufficient carbon dioxide or lactic acid over a limited period of time, to significantly alter blood gas results in the stagnant umbilical cord blood. Blood left in a doubly clamped umbilical cord $(6,7)$ at room temperature $(8,9)$ does not change in a clinically significant manner for at least 60 minutes after delivery. From the information on the patient presented above, it seems apparent that umbilical cord blood gas results probably do not change in a clinically significant manner when blood is stored "in situ" at body temperature over 20 minutes or more.

\section{"These reports suggest that the umbilical arteries have remained patent for a much longer period of time than in the case above."}

Others have reported even greater differences between umbilical venous and arterial $\mathrm{pH}$ and $\mathrm{PcO}_{2}$ associated with a prolapsed cord than presented here. $(10,11)$ These reports suggest that the umbilical arteries have remained patent for a much longer period of time than in the case above. Depending upon the forces involved and the interventions applied (manually elevating the head off the cord, for example), the umbilical arteries or even the umbilical vein may remain patent or have circulation restored during cord prolapse. 


\section{Key Points:}

- Typically, cord prolapse results in occlusion of the umbilical cord; as with other causes of cord occlusion, temporary restoration of umbilical artery blood flow results in a widened umbilical venoarterial $\mathrm{pH}$ difference.

- An occluded umbilical vessel will only reflect uteroplacental or uteroplacental-fetal status prior to the occlusion.

\section{Case 17: Occult Cord Prolapse:}

The mother was a 19-year-old, gravida 1 , para 0 , aborta 0 , with an intrauterine pregnancy at $401 / 7$ weeks gestation and mild preeclampsia. The cervix was ripened with Cytotec and then labor induced with Pitocin. Membranes were ruptured artificially; the fluid was clear. On the internal monitor, the FHR was approximately $130 \mathrm{bpm}$ with FHR accelerations and moderate variability. Deep variable decelerations lasting 60-90 seconds ensued, and Pitocin was discontinued without benefit. The FHR suddenly fell into the 50 s and remained down for the next six minutes, at which time FHR monitoring ended. Thirteen minutes later, an emergency cesarean delivery resulted in a male infant weighing $3828 \mathrm{~g}$. At delivery, a single loop of umbilical cord loosely encircled the neck, and another loop of the cord was noted alongside the fetal head (occult cord prolapse). At birth, the infant was flaccid and without spontaneous respirations. The infant was intubated, given PPV, and transferred to the NICU at about 10 minutes of life, still without spontaneous respirations or movement. Apgar scores were 2 at one minute, 3 at five and 10 minutes, and 5 at 20 minutes following delivery. The infant's first gasp was at the age of 19 minutes. Seizures occurred by age 3.5 hours.

Cord blood gas results were as follows:

\begin{tabular}{|c|c|c|}
\hline & Umbilical Vein & Umbilical Artery \\
\hline pH & 7.23 & 6.85 \\
\hline $\mathrm{PcO}_{2} \underset{(k \mathrm{~Pa})}{(\mathrm{mmHg})}$ & $\begin{array}{l}51 \\
6.80\end{array}$ & $\begin{array}{l}126 \\
16.80\end{array}$ \\
\hline $\mathrm{Po}_{2} \underset{(\mathrm{kPa})}{(\mathrm{mmHg})}$ & $\begin{array}{l}42 \\
5.60\end{array}$ & $\begin{array}{l}13 \\
1.73\end{array}$ \\
\hline BD (mmol/L) & 6 & 12 \\
\hline
\end{tabular}

At 43 minutes of age, an arterial blood gas in $70 \%$ oxygen was:

\begin{tabular}{|lc|l|}
\hline & & UAC \\
\hline $\mathrm{pH}$ & & 7.09 \\
\hline $\mathrm{Pco}_{2}$ & $\underset{(\mathrm{kPa})}{(\mathrm{mmHg})}$ & 16 \\
& 2.13 \\
\hline $\mathrm{Po}_{2}$ & $\begin{array}{c}(\mathrm{mmHg}) \\
\mathrm{(kPa})\end{array}$ & $\begin{array}{l}280 \\
37.33\end{array}$ \\
\hline \multicolumn{2}{|l|}{$\mathrm{BD}(\mathrm{mmol} / \mathrm{L})$} & 25 \\
\hline
\end{tabular}

A central hematocrit was $51 \%$. When the hematocrit was repeated
18 hours later, it was $40 \%$.

On follow-up pediatric examination at age three years and nine months, the infant had moderate choreoathetoid extrapyramidal cerebral palsy.

\section{Interpretation:}

The umbilical venous blood gas shows a mild respiratory acidosis and a slight increase in the $\mathrm{PO}_{2}$. The umbilical artery sample has a markedly low $\mathrm{pH}$, a very severely elevated $\mathrm{PCO}_{2}$, and a mildly elevated base deficit, i.e., a very severe respiratory and mild metabolic acidosis. The differences between the venous and arterial samples are extremely widened, suggesting cord occlusion with terminal fetal bradycardia. Following cord occlusion, there was an interval in which the umbilical vein remained occluded, but umbilical arterial blood flow was restored. The elevated venous $\mathrm{PO}_{2}$ suggests a brief period of time during which the umbilical vein was partially occluded, and circulation slowed. Johnson and Richards(11) have suggested that increased transit time secondary to diminished blood flow through a partially obstructed umbilical vein (diminished but not absent venous egress) results in an increased umbilical venous $\mathrm{PO}_{2}$. Additionally, the application of maternal supplemental oxygen may modestly augment the umbilical venous $\mathrm{PO}_{2}$ as well. $(12,13)$ Deep variable decelerations followed by the sudden and persistent fetal bradycardia beginning 19 minutes prior to delivery suggests cord prolapse. Indeed, the prolapsed cord was found at the cesarean section but had not been detected in the vaginal canal prior to surgery. The finding of prolapse on vaginal examination offers the potential of amelioration by gentle elevation of the fetal head.

A history of deep variable decelerations lasting more than $60 \mathrm{sec}-$ onds or a sudden, severe, and sustained FHR deceleration might prompt the clinician/obstetrician to consider placing the mother in Trendelenburg position and elevating the presenting part out of the pelvis while preparation for emergency cesarean delivery continues.(14) In that study, three of four such patients with deep variable decelerations lasting 60-90 seconds had dramatic resolution of the variable decelerations when the fetal head was elevated out of the pelvis; one of these three continued without severe variable decelerations even after the fetal head was again permitted to descend into the pelvis. In one of these three infants, the severe variable decelerations recurred after the head was permitted back into the pelvis, and cesarean delivery was performed. At delivery, an occult cord prolapse was detected. Neither nuchal cord nor other body part encirclement was reported in any of the four newborns. Certainly, not all occult cord prolapses present are detected at the time of cesarean delivery, as the delivering surgeon will only see an occult cord prolapse if it is visible within the surgical incision. It would be inappropriate to spend additional time searching for a vulnerable cord rather than extracting the infant. The newborns reported in this study were collected over approximately a three to four-month period, during which about 600-800 infants were delivered. (15) Therefore, it is quite likely that the diagnosis of occult cord prolapse is under-recognized. Only one infant was identified with occult cord prolapse, but as many as four may have occurred. This very small study suggests that the incidence of occult cord prolapse may be in the ballpark of one in 150 to one in 800 deliveries ( 0.13 to $0.67 \%)$.

NEONATOLOGY TODAY is interested in publishing manuscripts from Neonatologists, Fellows, NNPs and those involved in caring for neonates on case studies, research results, hospital news, meeting announcements, and other pertinent topics. Please submit your manuscript to: LomaLindaPublishingCompany@gmail.com 
Please note that the reported base deficit of $12 \mathrm{mmol} / \mathrm{L}$ is approximately 19 when the $\mathrm{pH}$ and $\mathrm{PCO}_{2}$ values are plotted on a SiggaardAndersen Alignment Nomogram. (16) This nomogram estimates blood base deficit. If one plots the same $\mathrm{pH}$ and $\mathrm{PCO}_{2}$ values on the Siggaard-Andersen Acid-Base Chart,(17) a chart that estimates extracellular fluid base deficit, then the estimate agrees with the reported value of 12 . Again, it is important to know the standard reporting practice of the blood gas laboratory at your hospital. Choosing one estimate of the base deficit over the other is no longer simply an academic matter. Criteria for deciding whether to treat a newborn with hypoxic-ischemic encephalopathy by cooling is decided in part by data that use extracellular base deficits. (18)

\section{Key Points:}

- $\quad$ Occult cord prolapse may be suspected not only on clinical grounds but also by analysis of the umbilical cord blood gas values.

- In the face of a history of severe variable decelerations, especially if followed by severe terminal bradycardia, and in the absence of any obvious cause of cord occlusion, occult prolapse becomes the most likely diagnosis.

- While preparation for emergency cesarean delivery continues, and with the mother in Trendelenburg position, the elevation of the fetal head out of the pelvis may result in a dramatic amelioration of either severe variable decelerations or a sudden, severe, and sustained FHR deceleration.

\section{References:}

1. Pomerance J. Umbilical cord blood gas casebook: Interpreting umbilical cord blood gases, Part VII J Perinat 2000,20:338-9.

2. Collea JV, Rabin SC, Weghorst GR, Quilligan EJ. The randomized management of term frank breech presentation: Vaginal vs cesarean section. Am J Obstet Gynecol 1978;131:186-95.

3. Levy H, Meier PR, Makowski EL. Umbilical cord prolapse. Obstet Gynecol 1984;64:499-502.

4. Barclay M, Umbilical cord prolapse and other cord accidents. In: Sciarra JJ [ed]: Gynecology and obstetrics, Philadelphia, JB Lippincott, 1989, p1.

5. Rayburn WF, Beynen A, Brinkman DL. Umbilical cord length and intrapartum complications. Obstet Gynecol 1981;57:450-2.

6. Ulrich JR, Ackerman BD. Changes in umbilical artery blood gas blood gas values with the onset of respiration. Biol Neonate. 1972;20:466-74.

7. Armstrong L, Stenson B. Effect of delayed sampling on umbilical cord arterial and venous lactate and blood gases in clamped and unclamped vessels. Arch Dis Child Fetal Neonatal Ed 2006;91:F342-5.

8. Duerbeck NB, Chaffin DG, Seeds JW. A practical approach to umbilical artery $\mathrm{pH}$ and blood gas determinations. Obstet Gynecol 1992;79:959-62.

9. Hilger JS, Holzman IR, Brown DR. Sequential changes in placental blood gases and $\mathrm{pH}$ during the hour following delivery. J Reprod Med 1981;26:305-7.

10. Smart PJ. Some observations on the vascular morphology of the foetal side of the human placenta. J Obstet Gynaecol Brit Commonw 1962;69:929-33.

11. Johnson JWC, Richards DS. The etiology of fetal acidosis as determined by umbilical cord acid-base studies. Am J Obstet Gynecol 1997;177:274-81.

12. Edelstone DI, Peticca BB, Goldblum LJ. Effects of maternal oxygen administration on fetal oxygenation during reductions in umbilical blood flow in fetal lambs. Am J Obstet Gynecol 1985;152:351-8.

13. Haruta M, Funato $T$, Sumida T, Shinkai T. The influence of oxygen inhalation for 30 to 60 minutes on fetal oxygenation. Nippon Sanka Fujinka Gakkai Zasshi 1984;36:1921-9.

14. Cohen WE, Schifrin BS, Doctor G. Elevation of the fetal pre- senting part: A method of intrauterine resuscitation. Am J Obstet Gynecol 1975;123:646-9.

15. Schifrin B, personal communication, 2010.

16. Siggaard-Andersen O. Blood acid-base alignment nomogram. Scand J Clin Lab Invest 1963, Radiometer reprint AS21.

17. Siggaard-Andersen O. An acid-base chart for arterial blood with normal and pathophysiological reference areas. Scand J Clin Laboratory Invest 1971:27:239-45.

18. Shankaran S, Laptook AR, Ehrenkranz RA, Tyson, JE, et al. Whole-body hypothermia for neonates with hypoxic-ischemic encephalo-pathy. N Engl J Med, 2005;353:1574-84.

Disclosure: The author has no disclosures.

NT
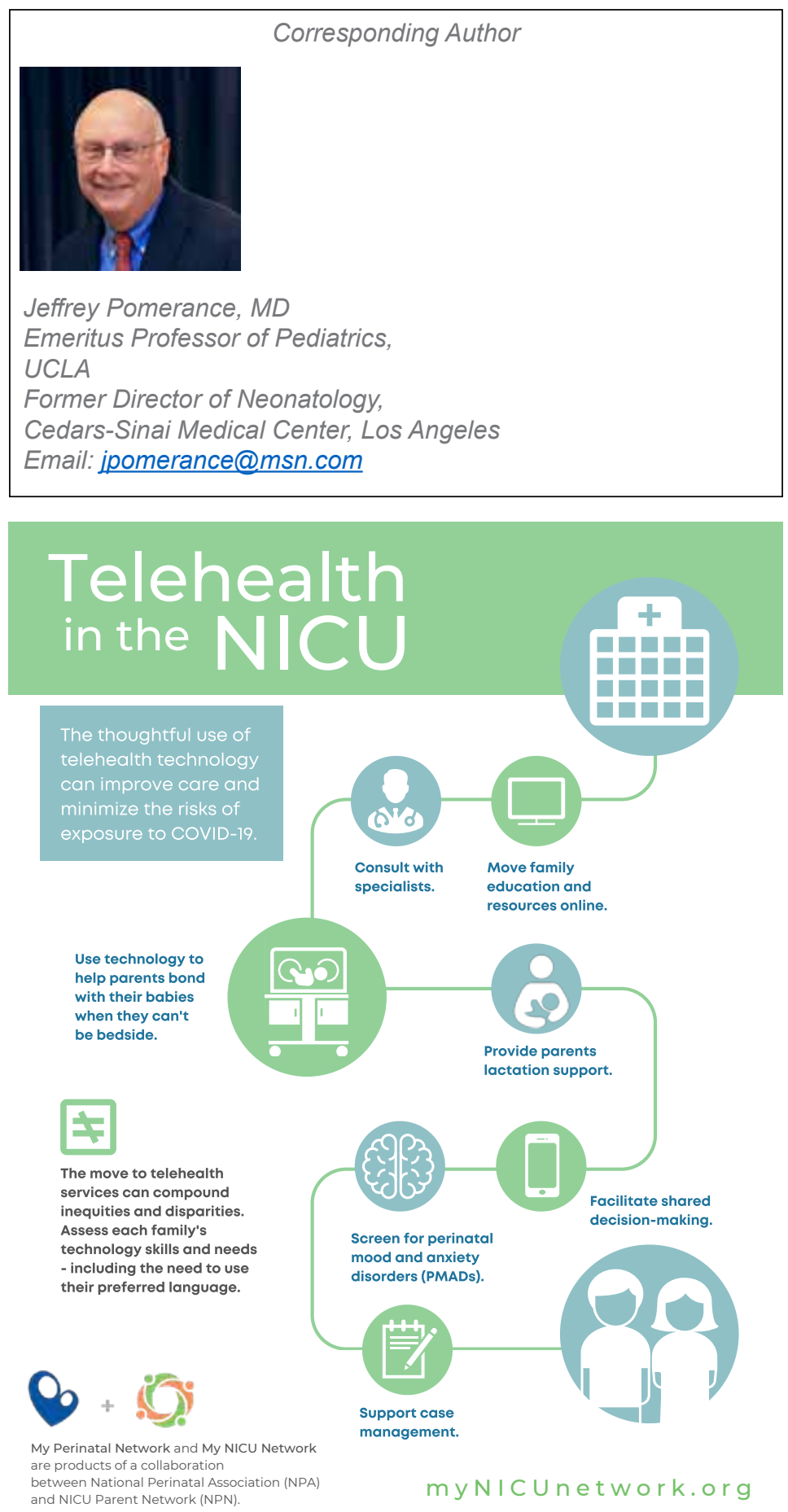